\title{
Trousseau sign in hypocalcemia
}

\author{
Habib U. Rehman MBBS, Shane Wunder MD
}

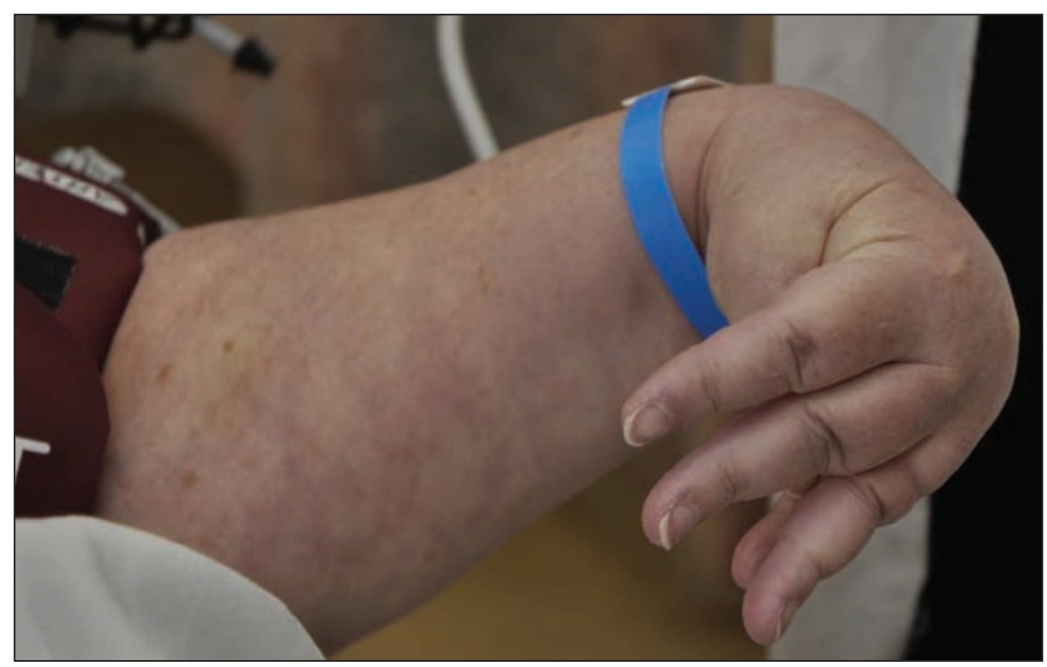

Figure 1: Trousseau sign in a 50-year-old woman with total thyroidectomy and hypocalcemia.

Competing interests: None declared.

This article has been peer reviewed.

Affiliations: From the Department of Internal Medicine (Rehman), Regina Qu'Appelle Health Region, Regina, Sask.; and the Department of Medicine (Wunder), University of Saskatchewan, Saskatoon, Sask.

CMAJ 2011. DOI:10.1503 /cmaj.100613

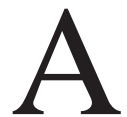
50-year-old woman presented with a two-day history of diarrhea, vomiting, progressive numbness around her mouth and generalized body cramps. One year before presentation, she had undergone a total thyroidectomy for a multinodular goiter. She also had a history of depression, hypertension and chronic renal impairment. She reported taking citalopram, rabeprazole for gastroesophageal reflux disease, calcium carbonate, levothyroxine and vitamin $B_{12}$. Her vital signs were stable. Trousseau sign was evidenced a few seconds after the sphygmomanometer cuff was inflated to more than the systolic blood pressure on the left upper arm (Figure 1, Appendix 1 , video available at www.cmaj.ca/cgi/content /full/cmaj.100613/DC1).

Laboratory investigations showed normal sodium, potassium and phosphorous values, but a corrected calcium level of 1.49 (normal 2.14 2.66) $\mathrm{mmol} / \mathrm{L}$, a magnesium level of 0.67 (normal $0.70-1.10) \mathrm{mmol} / \mathrm{L}$ and an alkaline phosphatase level of 365 (normal 40-135) U/L. The patient's serum creatinine level was 150 (normal $60-130) \mu \mathrm{mol} / \mathrm{L}$ and her urea level was 8.2 (normal 3.0-7.1) $\mathrm{mmol} / \mathrm{L}$. Results of thyroid func- tion tests showed a normal free thyroxine level of 17.1 (normal 9.0-19.0) pmol/L and an elevated thyroid-stimulating hormone level of 6.34 (normal 0.49-4.67) mIU/L. Parathyroid hormone was less than 1 (normal 1.3-6.8) ng/L. An electrocardiogram showed a corrected QT interval of 552 (normal 451-470) ms.

A diagnosis of iatrogenic hypoparathyroidism was made. Hypocalcemia was most likely caused by vomiting, resulting in malabsorption of oral calcium carbonate. The patient's symptoms, signs and biochemical abnormalities resolved after the intravenous administration of calcium gluconate and magnesium, and she was discharged home on oral calcium supplements and alfacalcidol.

Trousseau sign is elicited in hypocalcemia when the ionized calcium level is $1.75-2.25$ $\mathrm{mmol} / \mathrm{L} .{ }^{1}$ The hand adopts a characteristic posture when the sphygmomanometer cuff is inflated above the systolic blood pressure within 3 minutes. The metacarpophalangeal joints are flexed, the interphalangeal joints of the fingers and thumb are extended and the thumb adopts a posture of opposition (main d'accoucheur). ${ }^{2}$ Trousseau sign is more specific than Chvostek sign for latent tetany, which can be caused by hypocalcemia, hypomagnesemia and metabolic alkalosis. ${ }^{3.4}$ A positive Trousseau sign is seen in $1 \%-4 \%$ of healthy people. ${ }^{1}$ The sensitivity of the sign is not known, but the sign can be absent in patients with definite hypocalcemia.

\section{References}

1. Shoback D, Marcus R, Bikle D. Metabolic bone disease. In: Greenspan FS, Gardner DG, editors. Basic and clinical endocrinology. 3rd ed. Los Altos (CA): Lange Medical Publications; 2004. p. 324.

2. Trousseau A. Lectures on clinical medicine, delivered at the Hôtel-Dieu, Paris. 3rd ed. [Translated by Sir John Cormack]. London (UK): New Sydenham Society; 1872.

3. Ito N, Fukumoto S. Symptoms and management of tetany. Clin Calcium 2007:17:1234-9.

4. Flink EB. Magnesium deficiency. Etiology and clinical spectrum. Acta Med Scand Suppl 1981;647:125-37.

See video online of the Trousseau sign:
www.cmaj.ca/cgi/content/full/cmaj
.100613/DC1

